\title{
Neurotensin Modulates the Migratory and Inflammatory Response of Macrophages under Hyperglycemic Conditions
}

\author{
Liane I. F. Moura, ${ }^{1,2}$ Lucília Silva, ${ }^{1}$ Ermelindo C. Leal, ${ }^{1}$ Ana Tellechea, ${ }^{1,3}$ \\ Maria Teresa Cruz, ${ }^{1,3}$ and Eugénia Carvalho ${ }^{1,4}$ \\ ${ }^{1}$ Center for Neuroscience and Cell Biology, University of Coimbra, 3004-517 Coimbra, Portugal \\ ${ }^{2}$ CIEPQPF, Chemical Engineering Department, FCTUC, University of Coimbra, 3030-790 Coimbra, Portugal \\ ${ }^{3}$ Faculty of Pharmacy, University of Coimbra, 3000-548 Coimbra, Portugal \\ ${ }^{4}$ The Portuguese Diabetes Association (APDP), Rua Do Salitre, No. 118-120, 1250-203 Lisboa, Portugal
}

Correspondence should be addressed to Eugénia Carvalho; ecarvalh@cnc.uc.pt

Received 8 April 2013; Revised 24 June 2013; Accepted 28 June 2013

Academic Editor: Senthil K. Venugopal

Copyright (C) 2013 Liane I. F. Moura et al. This is an open access article distributed under the Creative Commons Attribution License, which permits unrestricted use, distribution, and reproduction in any medium, provided the original work is properly cited.

\begin{abstract}
Diabetic foot ulcers (DFUs) are characterized by an unsatisfactory inflammatory and migratory response. Skin inflammation involves the participation of many cells and particularly macrophages. Macrophage function can be modulated by neuropeptides; however, little is known regarding the role of neurotensin (NT) as a modulator of macrophages under inflammatory and hyperglycemic conditions. RAW 264.7 cells were maintained at $10 / 30 \mathrm{mM}$ glucose, stimulated with/without LPS $(1 \mu \mathrm{g} / \mathrm{mL})$, and treated with/without NT(10 nM). The results show that NT did not affect macrophage viability. However, NT reverted the hyperglycemia-induced impair in the migration of macrophages. The expression of IL- 6 and IL- $1 \beta$ was significantly increased under $10 \mathrm{mM}$ glucose in the presence of NT, while IL-1 $\beta$ and IL-12 expression significantly decreased under inflammatory and hyperglycemic conditions. More importantly, high glucose modulates NT and NT receptor expression under normal and inflammatory conditions. These results highlight the effect of NT on cell migration, which is strongly impaired under hyperglycemic conditions, as well as its effect in decreasing the proinflammatory status of macrophages under hyperglycemic and inflammatory conditions. These findings provide new insights into the potential therapeutic role of NT in chronic wounds, such as in DFU, characterized by a deficit in the migratory properties of cells and a chronic proinflammatory status.
\end{abstract}

\section{Introduction}

Diabetes mellitus (DM) is characterized by an impaired blood glucose homeostasis, and it affects millions of people in the world [1]. Diabetes can cause poor circulation in the extremities, particularly in people with neuropathy, and long-term diabetes can compromise the immune system increasing the incidence of infections in the patients. One of the most debilitating and costly complications of diabetes is the development of chronic foot ulcers. This disease affects approximately $15 \%$ of the diabetic population [2-4]. It can diminish physical activity, and, in extreme cases, diabetic foot ulcerations (DFUs) can lead to lower-limb amputations [5]. Chronic inflammation is a major characteristic of diabetic cutaneous wounds. Wound inflammation has a fundamental role in tissue regeneration [6], while leukocyte dysfunction to the wound site has been shown to contribute to the development of nonhealing wounds [7]. Indeed, diabetic patients show impaired leukocyte function, which has been correlated with hyperglycemia [8]. Studies performed in diabetic patients revealed that normalization of blood glucose levels through insulin administration can improve and ultimately restore the functional activity of neutrophils [9].

It is also well known that an imbalance between proinflammatory and anti-inflammatory cytokines in the diabetic wound tissue compromises the time resolution of inflammation and consequently the healing process [10]. Macrophages play a crucial role in the modulation of the inflammatory 
response since they can be phenotypically polarized to the classical activated macrophages that stimulate the inflammatory process or to the alternatively activated macrophages that play a role in the resolution of inflammation [11]. Recent results demonstrated that in a diabetic mouse model, impairment in glucose metabolism can cause changes in the macrophage response to lipopolysaccharide (LPS), namely, increased secretion of interleukin 12 (IL-12) and TNF- $\alpha$ [12].

In addition to the involvement of inflammation in wound repair responses, various studies suggest that the neuroendocrine system also modulates wound healing [13], specifically through neuropeptides, such as substance $\mathrm{P}$ (SP) and neurotensin (NT) [14-18]. NT is a bioactive tridecapeptide that is widely distributed through the brain and the gastrointestinal tract $[14,19]$. It regulates a wide range of biological functions, such as the gastric system and inflammatory processes in the lung $[14,18]$. Furthermore, NT modulates the immune response, as it interacts with leukocytes, peritoneal mast cells, and dendritic cells, stimulating cytokine release and chemotaxis [20-22]. In particular, neuropeptides, such as NT, are important in modulating macrophage function, due to their direct interaction with macrophages leading to suppression of the production of proinflammatory cytokines and iNOS expression, demonstrating a protective effect in inflammatory conditions $[23,24]$.

NT mediates its functions through its two G protein coupled receptors: neurotensin receptor 1 (NTR1) and neurotensin receptor 2 (NTR2) (high and low affinity receptors, resp.). A third receptor, the neurotensin receptor 3 (NTR3), is an intracellular, non $G$ protein coupled receptor $[5,25]$. Although NT has been implicated in modulating immune responses and macrophage function, its molecular mechanisms of action, under either hyperglycemic or inflammatory conditions or both, remain unclear.

Therefore, this study aims to determine the effect of NT in macrophages function under hyperglycemic and inflammatory conditions.

\section{Materials and Methods}

2.1. Materials. LPS from Escherichia coli (serotype 026 : B6) was obtained from Sigma Chemical Co. (St. Louis, MO, USA), and NT was obtained from Bachem (Weil am Rhein, Germany). Fetal calf serum was purchased from Invitrogen (Paisley, UK). The protease and phosphatase inhibitor cocktails were obtained from Roche (Mannheim, Germany).

The antibodies against phospho (p), p-p44/42 MAPK, pp38 MAPK, I $\kappa \mathrm{B} \alpha$, and total AKT were purchased from Cell Signaling Technologies (Danvers, MA, USA). The antibodies against pAKT (Ser 473) and the NT receptors were purchased from Santa Cruz Biotechnology (Santa Cruz, California, USA), and the antibodies against total p38 MAPK and p44/42MAPK were purchased from BioLegend (San Diego, CA, USA). The antibody against actin was purchased from Millipore Corporation (Bedford, MA).

All primers were obtained from IDT (Ebersberg, Germany). SYBR green was obtained from Bio-Rad (Hercules, CA, USA), and High Capacity cDNA Reverse Transcription kit was obtained from Applied Biosystems (Carlsbad, CA, USA).

The alkaline phosphatase-linked secondary antibodies and the enhanced chemifluorescence (ECF) reagent were obtained from GE Healthcare (Chalfont St. Giles, UK), and the polyvinylidene difluoride (PVDF) membranes were from Millipore Corporation (Bedford, MA, USA). TRIzol reagent was purchased from Invitrogen (Barcelona, Spain). All other reagents were from Sigma Chemical Co. (St. Louis, MO, USA) or from Merck (Darmstadt, Germany).

2.2. Macrophage Cell Culture. RAW 264.7 (mouse leukaemic monocyte macrophage cell line) cells were cultured in DMEM medium, $\mathrm{pH} 7.4$, supplemented with $10 \%$ heat inactivated fetal bovine serum (FBS), $3.02 \mathrm{~g} / \mathrm{L}$ sodium bicarbonate, $100 \mathrm{U} / \mathrm{mL}$ penicillin, and $100 \mu \mathrm{g} / \mathrm{mL}$ streptomycin, at $37^{\circ} \mathrm{C}$ in a humidified incubator containing $5 \% \mathrm{CO}_{2}$. Subculturing was performed according to ATCC recommendations. The RAW 264.7 cell line was purchased from ATCC (number TIB-71).

2.3. Treatments of Macrophages. The cells were incubated in $10 \mathrm{mM}$ (normal glucose) or $30 \mathrm{mM}$ (high glucose) D-glucose, for 15 days, before the beginning of the experiments.

For the viability assay, we used the cells incubated with high glucose for 15 days. Macrophages were treated with $1 \mu \mathrm{g} / \mathrm{mL}$ of LPS, with 10,50 , or $100 \mathrm{nM}$ of NT alone, or with a combination of both treatments (NT plus LPS) for 1, 3, 5, and 7 days. These dose and treatment protocols were selected to evaluate the role of NT in macrophage cell viability after exposure to an acute ( 1 and 3 days) and a chronic (5 and 7 days) hyperglycemic and inflammatory state.

For the migration assay, RAW 264.7 cells were incubated with $1 \mu \mathrm{g} / \mathrm{mL}$ of LPS alone, with $10 \mathrm{nM}$ of NT alone, or with a combination of both treatments $(10 \mathrm{nM}$ NT plus $1 \mu \mathrm{g} / \mathrm{mL}$ LPS) in DMEM medium containing $2 \%$ of inactivated fetal calf serum.

In order to study the signal transduction pathways, macrophages were incubated with $1 \mu \mathrm{g} / \mathrm{mL}$ of LPS alone or with $10 \mathrm{nM}$ of NT alone or a combination of both treatments (10 nM NT plus $1 \mu \mathrm{g} / \mathrm{mL}$ LPS) for $5,15,30$, or $60 \mathrm{~min}$. The cells were incubated with the same treatments for $24 \mathrm{~h}$ to evaluate the levels of NT receptors and for $6 \mathrm{~h}$ in the real-time PCR studies.

2.4. MTT Viability Assay. RAW $264.7\left(8 \times 10^{4}\right.$ cells/well $)$ cells were plated in 48 -well plates in $430 \mu \mathrm{L}$ of DMEM. After cell treatment, as described previously, $43 \mu \mathrm{L}$ of MTT solution $(5 \mathrm{mg} / \mathrm{mL})$ were added to each well. The plates were further incubated at $37^{\circ} \mathrm{C}$ for $1 \mathrm{~h}$ in a humidified incubator containing $5 \% \mathrm{CO}_{2} .300 \mu \mathrm{L}$ of acidic isopropanol $(0.04 \mathrm{NHCl}$ in isopropanol) were then added to each well and mixed in order to dissolve the dark blue crystals of formazan. Acidic isopropanol was collected to an ELISA microplate, and formazan quantification was performed using an ELISA automatic microplate reader (SLT, Austria) at $570 \mathrm{~nm}$, with a reference wavelength of $620 \mathrm{~nm}$. 
2.5. In Vitro Scratch Migration Assay. RAW $264.7\left(4 \times 10^{5}\right.$ cells/well) cells were resuspended in $3 \mathrm{~mL}$ of DMEM medium in $\mu$-Dish ${ }^{35 \mathrm{~mm} \text {, high }}$ (ibidi). After $24 \mathrm{~h}$, a "scratch" was made, with a pipette tip, in the cell monolayer in a straight line to create an area without cells. The medium was removed, and cells were washed two times with PBS. DMEM medium containing $2 \%$ of inactivated fetal calf serum was then added to the cells to diminish cell proliferation. The cells were incubated as described previously and allowed to migrate for $24 \mathrm{~h}$. Photographs were captured with a coupled AxioCam MR3 camera with PALM reflector and 5x objective, using an inverted Axiovert 200. A specific numbered/lettered area was chased to permit later recognition of the photographed area. After the incubation period, photographs were taken in the same area where the first photograph was taken. Photographs were analysed, and the number of cells in the scratch area was counted. For the analysis, the number of cells in the zero point was taken into account.

2.6. Western Blotting. RAW $264.7\left(1.5 \times 10^{6}\right.$ cells/well $)$ cells were seeded in 6-well plates and treated as described before. Cells were then washed twice with ice-cold PBS buffer and lysed with RIPA buffer (50 mM Tris $\mathrm{HCl} \mathrm{pH} 8,150 \mathrm{mM} \mathrm{NaCl}$, $1 \%$ NP-40 (Nonidet P-40), 0.5\% Sodium Deoxycholate, $0.1 \%$ SDS, 2 mM EDTA, protease inhibitor cocktail, phosphatase inhibitor cocktail, and $1 \mathrm{mM}$ DTT). Protein concentration was determined using the bicinchoninic acid method, and cell lysates were denatured at $95^{\circ} \mathrm{C}$, for $5 \mathrm{~min}$, in sample buffer (0.125 mM Tris pH 6.8; 2\% w/v SDS; $100 \mathrm{mM} \mathrm{DTT;} 10 \%$ glycerol; and bromophenol blue) for its use in western blot analysis. $30 \mu \mathrm{g}$ of total protein were resolved on $10 \%$ SDSPAGE and transferred to PVDF membranes. The membranes were blocked with $5 \%(\mathrm{w} / \mathrm{v})$ fat-free dry milk in Trisbuffered saline containing $0.1 \%(\mathrm{v} / \mathrm{v})$ Tween 20 (TBS-T), for $1 \mathrm{~h}$, at room temperature. After blocking and washing, membranes were incubated overnight at $4^{\circ} \mathrm{C}$ with the primary antibodies against the different proteins of interest: p-p38 MAPK (1:1000), I $\kappa$ B- $\alpha$ (1:1000); p-p44/42MAPK $(1: 1000)$, p-AKT $(1: 500)$, NTR1 $(1: 500)$, NTR2 $(1: 500)$, or NTR3 (1:500). After incubation, membranes were washed and incubated for $1 \mathrm{~h}$ at room temperature with alkaline phosphatase-conjugated antirabbit antibody $(1: 5000)$ or alkaline phosphatase-conjugated antimouse antibody $(1: 5000)$. The membranes were exposed to ECF reagent followed by scanning for blue excited fluorescence on the VersaDoc (Bio-Rad Laboratories, Amadora, Portugal). To test whether similar amounts of protein for each sample were loaded, the membranes were stripped and reprobed with antibodies for total, p38 MAPK, p44/42MAPK, and AKT or with an antiactin antibody, and blots were developed with alkaline phosphatase-conjugated secondary antibodies and visualized by enhanced chemifluorescence. The generated signals were analyzed using the Image-Quant TL software.

2.7. Real-Time RT-PCR. Cells $\left(2 \times 10^{6}\right.$ cells/well $)$ were seeded in 6-well plates and treated as described before. Total RNA was isolated from cells with the TRIzol reagent according to the manufacturer's instructions, and concentration was
TABLE 1: Forward and reverse primers sequences used in RT-PCR.

\begin{tabular}{lc}
\hline Primer & $5^{\prime}$-3 $^{\prime}$ sequence (forward; reverse) \\
\hline NT & For: AATGTTTGCAGCCTCATAAATAAC \\
& Rev: TGCCAACAAGGTCGTCATC \\
NTR1 & For: GGCAATTCCTCAGAATCCATCC \\
& Rev: ATACAGCGGTCACCAGCAC \\
NTR2 & For: GCCATTACTAACAGTCTAAGC \\
& Rev: GCAATTCGTCCTATTCTACAC \\
NTR3 & For: ATGGCACAACTTCCTTCTG \\
& Rev: AGAGACTTGGAGTAGACAATG \\
IL-6 & For: TTCCATCCAGTTGCCTTC \\
& Rev: TTCTCATTTCCACGATTTCC \\
TNF- $\alpha$ & For: CAAGGGACTAGCCAGGAG \\
& Rev: TGCCTCTTCTGCCAGTTC \\
Il-10 & For: CCCTTTGCTATGGTGTCCTTTC \\
& Rev: ATCTCCCTGGTTTCTCTTCCC \\
IL-1 $\beta$ & For: ACCTGTCCTGTGTAATGAAAG \\
& Rev: GCTTGTGCTCTGCTTGTG \\
IL-12 & For: CAGAAGCTAACCATCTCCTGGTTTG \\
& Rev: TCGGGAGTAATTTGGTGCTTCACAC \\
HPRT1 & For: GTTGAAGATATAATTGACACTG \\
& Rev: GGCATATCCAACAACAAAC \\
\hline
\end{tabular}

determined by OD260 measurement using the NanoDrop spectrophotometer (Thermo Scientific, USA). First strand cDNA was synthesized using High Capacity cDNA Reverse Transcription. Briefly, $2 \mu \mathrm{L}$ of $10 \mathrm{x}$ RT Buffer, $0.8 \mu \mathrm{L}$ of $25 \mathrm{x}$ dNTP Mix, $2 \mu \mathrm{L}$ of $10 \mathrm{x}$ RT random primers, $1 \mu \mathrm{L}$ of MultiScribe Reverse Transcriptase, and $4.2 \mu \mathrm{L}$ of nuclease free $\mathrm{H}_{2} \mathrm{O}$ were added to $10 \mu \mathrm{L}$ of RNA (1 $\mu \mathrm{g})$ sample. Then, real-time RT-PCR was performed in a Bio-Rad iCycler iQ5. For each reaction, $10 \mu \mathrm{L}$ volume were used containing $2.5 \mu \mathrm{L}$ cDNA, $5 \mu \mathrm{L} 2 \mathrm{x}$ SYBR Green Supermix, $1 \mu \mathrm{L}$ of each primer $(250 \mathrm{nM})$, and $0.5 \mu \mathrm{L}$ of $\mathrm{H}_{2} \mathrm{O}$ PCR grade. Primer sequences are given in Table 1. Gene expression changes were analyzed using iQ5 optical system software v2. The software enables analysis of the results with the Pfaffl method [26]. The results were normalized using a reference gene, hypoxanthine phosphoribosyltransferase 1 (HPRT-1), that was selected based on our previous results demonstrating that it does not change under these conditions.

2.8. Statistical Analysis. Results are expressed as mean \pm SEM. Statistical analysis was performed using one-way ANOVA followed by Tukey's multiple comparison tests or through the unpaired Student's $t$ test using GraphPad Prism (GraphPad Software Inc., San Diego, CA, USA). $P$ values less than 0.05 were considered statistically significant.

\section{Results}

All experiments were performed using RAW 267.4 cells incubated with either $10 \mathrm{mM}$ glucose (normal glucose) or $30 \mathrm{mM}$ glucose (high glucose), for a period of 15 days. 


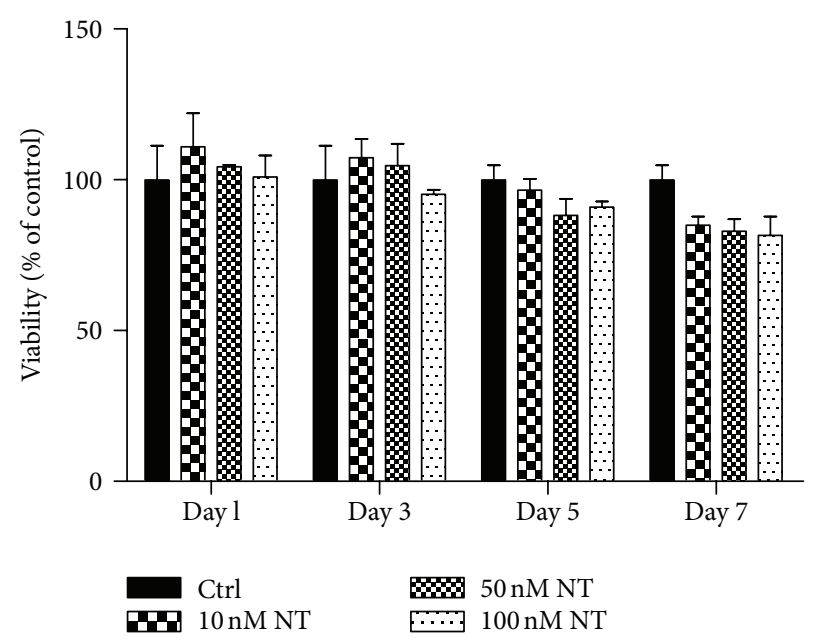

(a)

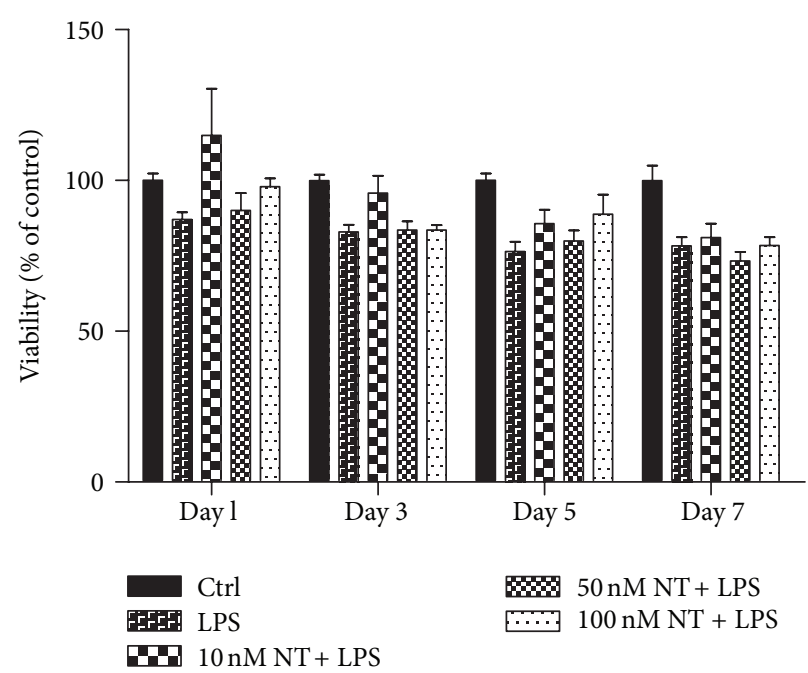

(b)

FIGURE 1: Viability of macrophages, under either 10 or $30 \mathrm{mM}$ glucose, by MTT assay. RAW 264.7 cells were plated at $8 \times 10^{4} /$ well and were treated with 10, 50 or, $100 \mathrm{nM}$ of NT (a) or in combination with $1 \mu \mathrm{g} / \mathrm{mL}$ of LPS (b) for 7days. After, 1, 3, 5, or 7 days of incubation, MTT assay was performed as described in "Materials and Methods." Absorbance quantification was performed using a microplate reader at $570 \mathrm{~nm}$, with a reference wavelength of $620 \mathrm{~nm}$. Results are presented as mean \pm SEM of three independent experiments.

3.1. Cell Viability under Hyperglycemic Conditions. NT treatment did not change the viability of macrophages under hyperglycemic conditions either in the absence or presence of LPS (Figures 1(a) and 1(b), resp.). Since no major differences were observed between the different doses of NT used (10, 50, or $100 \mathrm{nM}$ ), the following experiments were performed using $10 \mathrm{nM}$ of NT.

\subsection{Migration of Macrophages under Normal or Hyperglycemic} Conditions. Our results show that under normoglycemic conditions (10 mM glucose), NT treatment did not stimulate macrophage migration, either in the absence or in the presence of LPS (Figures 2(a) and 2(c)). However, under hyperglycemic conditions ( $30 \mathrm{mM}$ glucose), NT significantly increased cell migration compared to control $(P<0.05)$ as shown in Figures 2(b) and 2(c). Moreover, high glucose alone $(P<0.01)$ or in combination with LPS treatment $(P<$ $0.05)$ significantly decreased macrophage migration when compared with normoglycemic conditions (Figures 2(b) and 2(c)).

These results demonstrate that macrophage migration is impaired under hyperglycemic conditions. Moreover, this impairment is partially reverted by NT treatment.

3.3. Inflammatory Cytokine Expression under Normal and Hyperglycemic Conditions. In order to address the pattern of cytokine gene expression that is involved in wound healing processes stimulated by NT alone or in the presence of LPS, we measured gene expression for the proinflammatory cytokines IL-6, TNF- $\alpha$, IL-1 $\beta$, and IL-12 and for the antiinflammatory cytokine IL-10 in macrophages, as indicated in Figure 3.
Under $10 \mathrm{mM}$ glucose, NT induced a significant overexpression of IL-6 $(P<0.05)$ and IL-1 $\beta(P<0.05)$. On the other hand, under $30 \mathrm{mM}$ glucose, NT significantly increased the expression of TNF- $\alpha(P<0.05)$ and IL-1 $\beta(P<0.05)$, as compared to high glucose alone (Figure 3 ).

Moreover, in LPS-treated cells, NT treatment significantly increased TNF- $\alpha(P<0.05)$ and IL-12 $(P<0.05)$ expression under $10 \mathrm{mM}$ glucose, when compared with LPS-treated cells (Figure 3). However, NT did not alter the expression of these genes under hyperglycemic conditions. Interestingly, hyperglycemia alone increased the expression of IL-6 $(P<0.05)$ and decreased the expression of IL-1 $\beta(P<0.05)$, when compared to normal glycemia under inflammatory conditions (Figure 3). Overall, these results show that NT modulates the inflammatory profile of macrophages; however, this effect was not observed under hyperglycemic conditions, as observed in Figure 3.

\subsection{Modulation of Intracellular Signaling Pathways by NT} in LPS Treated Macrophages under Either 10 Or $30 \mathrm{mM}$ Glucose. The expression of proinflammatory molecules is tightly regulated by several transcription factors and signaling pathways. Among these pathways, mitogen-activated protein kinases (MAPKs) and the transcription factor NF- $\kappa \mathrm{B}$ constitute signaling molecules that play critical roles in the orchestration of an inflammatory response. The effect of NT on LPS-induced molecular pathway activation, under either 10 or $30 \mathrm{mM}$ glucose, was assessed by measuring the levels of the phosphorylated forms of MAP kinases (p38 MAPK, p44/42 MAPK, and SAPK/JNK) and PKB/AKT by western blot. The importance of the transcription factor NF- $\kappa$ B was also evaluated by determination of the protein levels of its inhibitory protein, $\mathrm{I} \kappa \mathrm{B}-\alpha$, as shown in Figures $4(\mathrm{a})$ and $4(\mathrm{~b})$. 

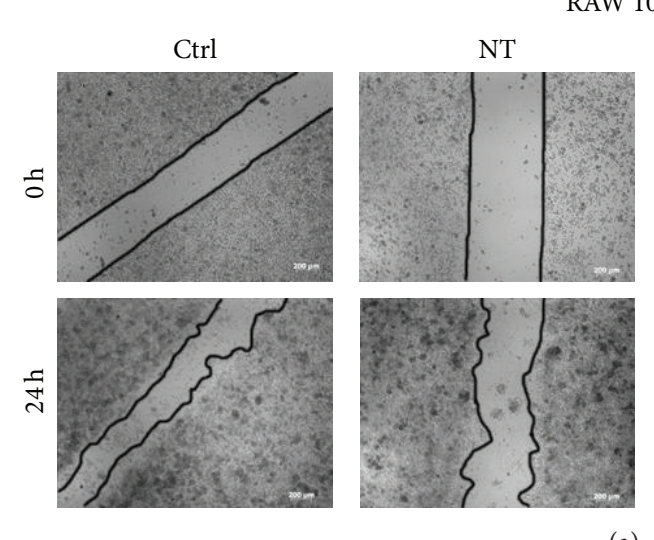

RAW $10 \mathrm{mM}$ glucose
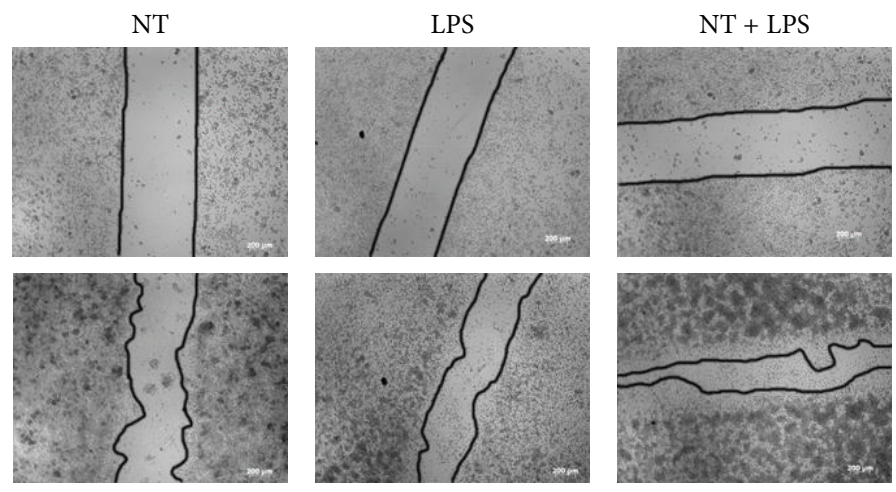

(a)

RAW $30 \mathrm{mM}$ glucose
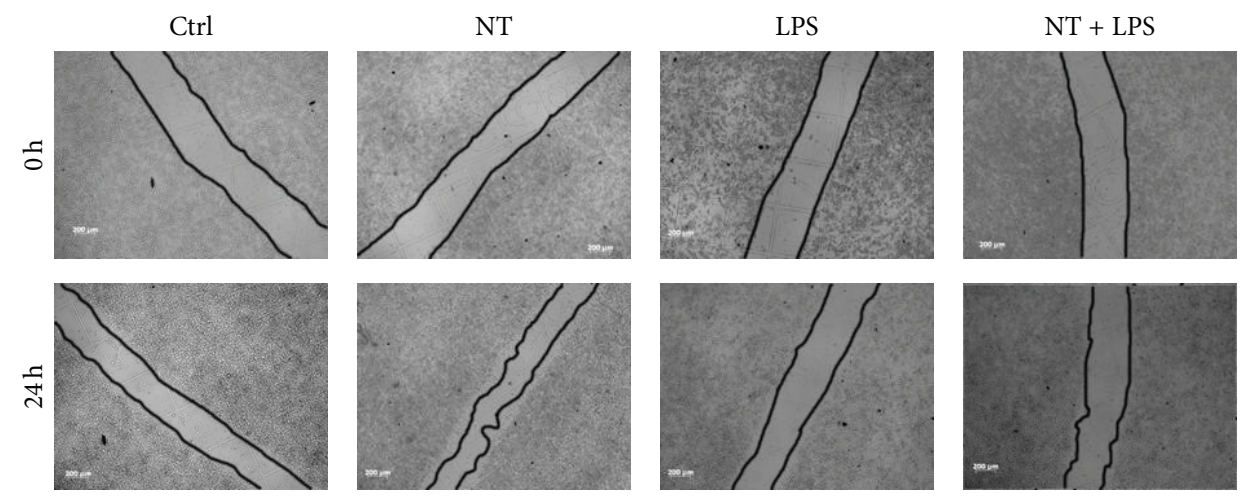

(b)

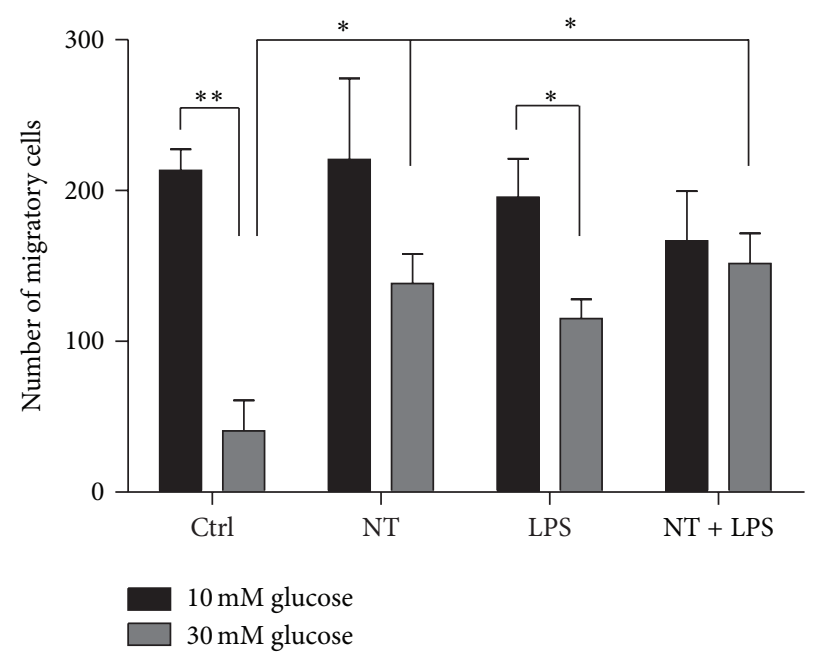

(c)

FIGURE 2: Migration of macrophages at 10 (a) and $30 \mathrm{mM}$ (b) glucose, by in vitro scratch assay. (c): number of migrating cells (referred before). Cells were plated at $4 \times 10^{5} /$ well and treated with $10 \mathrm{nMNT}$ or $1 \mu \mathrm{M} / \mathrm{mL}$ LPS or both, during $24 \mathrm{~h}$. The scratch assay was performed as described in "Material and Methods." The images were acquired by transmission microscopy, and photographs were taken before cell treatment $(0 \mathrm{~h})$ and $24 \mathrm{~h}$ after treatments. Magnification used was $40 \mathrm{x}$. Results are presented as mean \pm SEM of three independent experiments. ${ }^{*} P<0.05$; ${ }^{* *} P<0.01$. 
IL-6

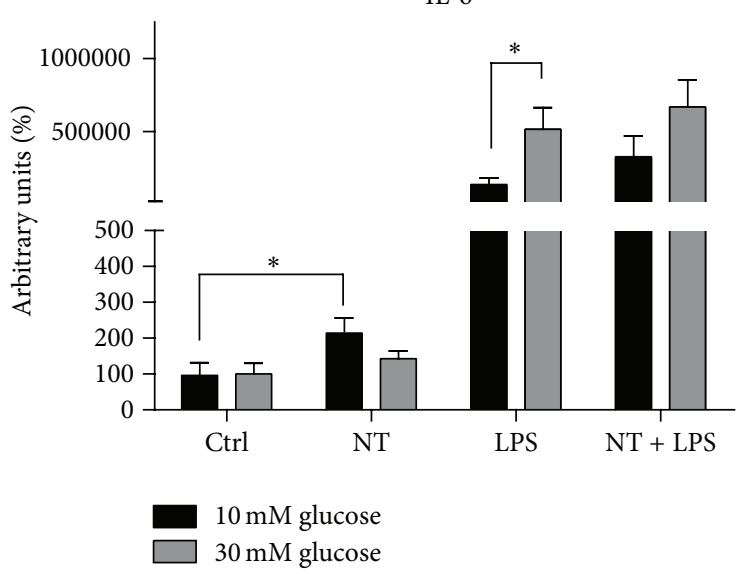

(a)

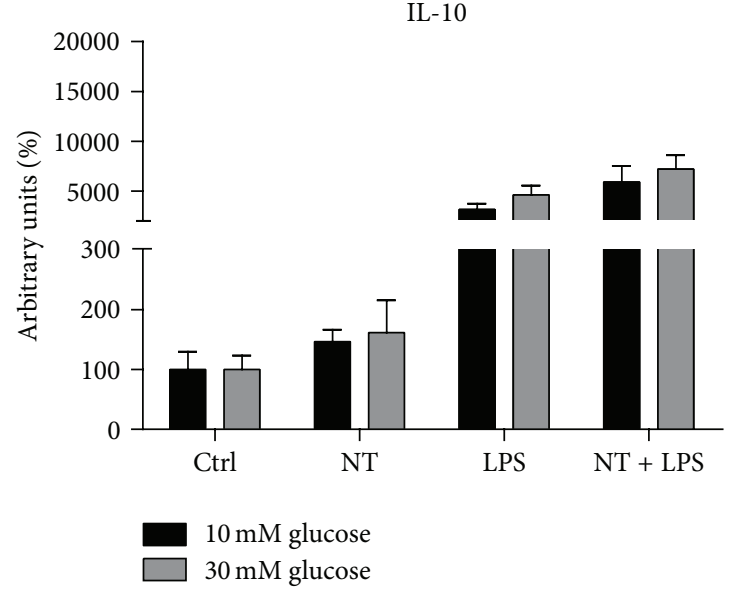

(c)

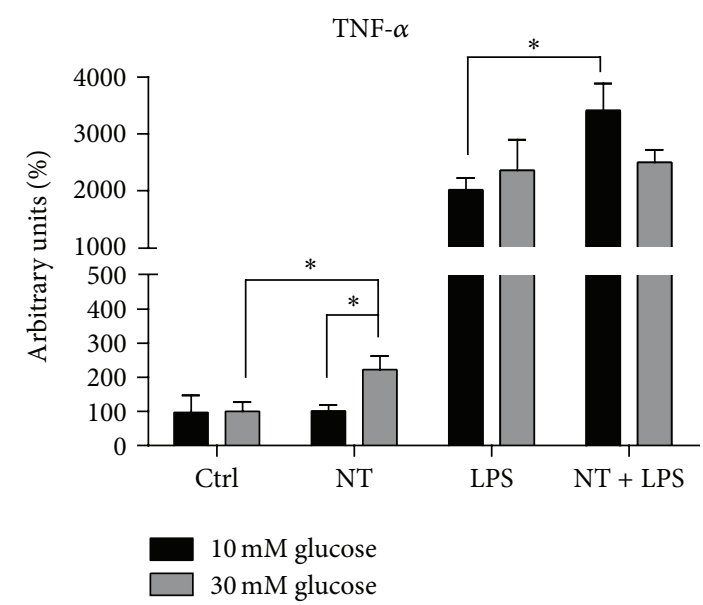

(b)

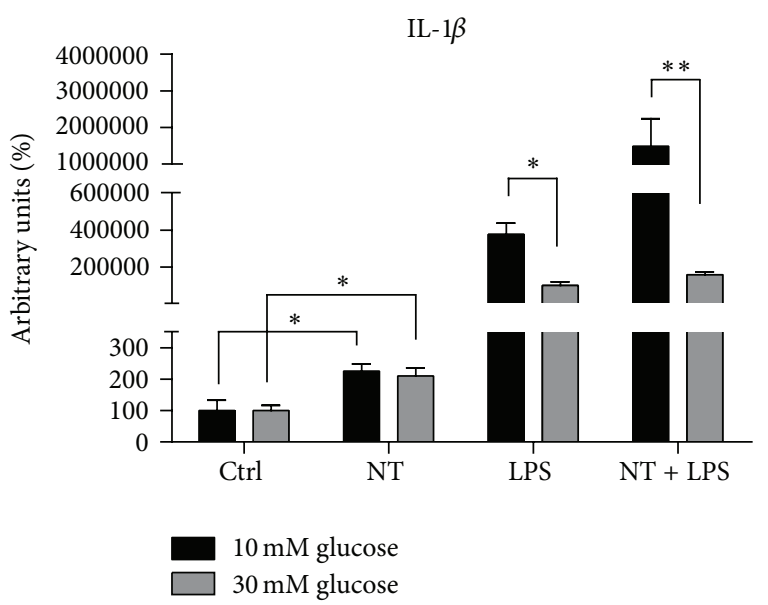

(d)

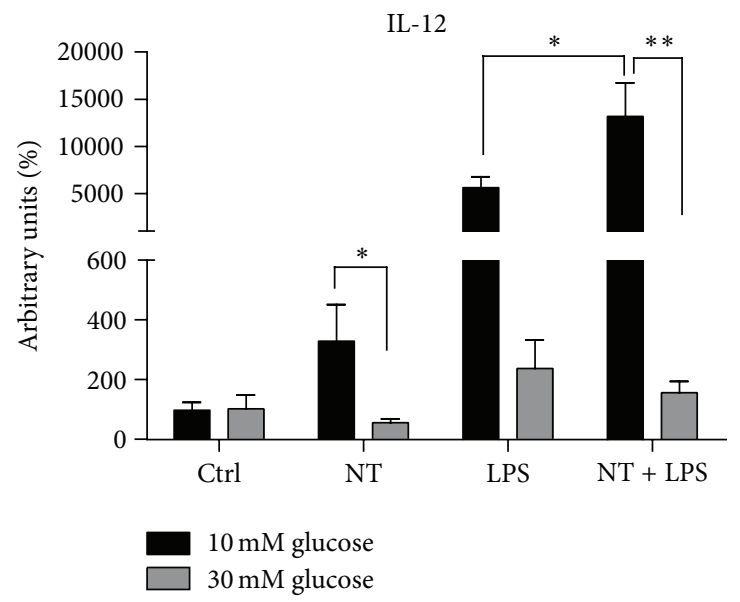

(e)

Figure 3: Expression of inflammatory cytokines IL-6, TNF- $\alpha$, IL-10, IL-1 $\beta$, and IL-12 in macrophages, at 10 and $30 \mathrm{mM}$ glucose, by real-time PCR. Cells were plated at $2 \times 10^{6} /$ well and treated with $10 \mathrm{nM} \mathrm{NT}$ or $1 \mu \mathrm{g} / \mathrm{mL}$ LPS or both, during $6 \mathrm{~h}$. Total RNA was isolated as described in "Materials and Methods." The relative gene expression is indicated as arbitrary units and was obtained after normalization with the HPRT gene. Results are presented as mean \pm SEM of six to ten independent experiments. ${ }^{*} P<0.05 ;{ }^{* *} P<0.01$. 

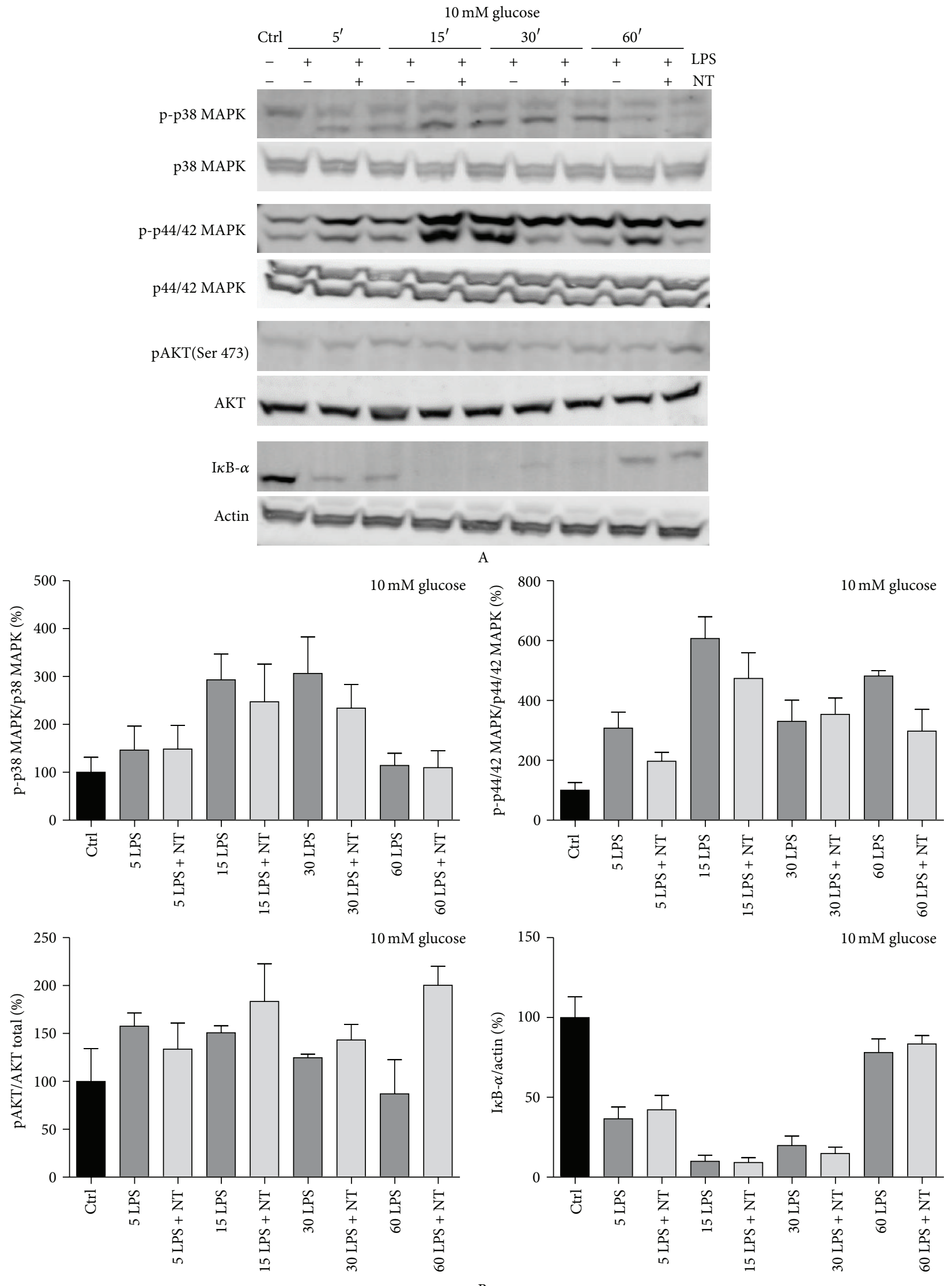

(a)

FIGUre 4: Continued. 

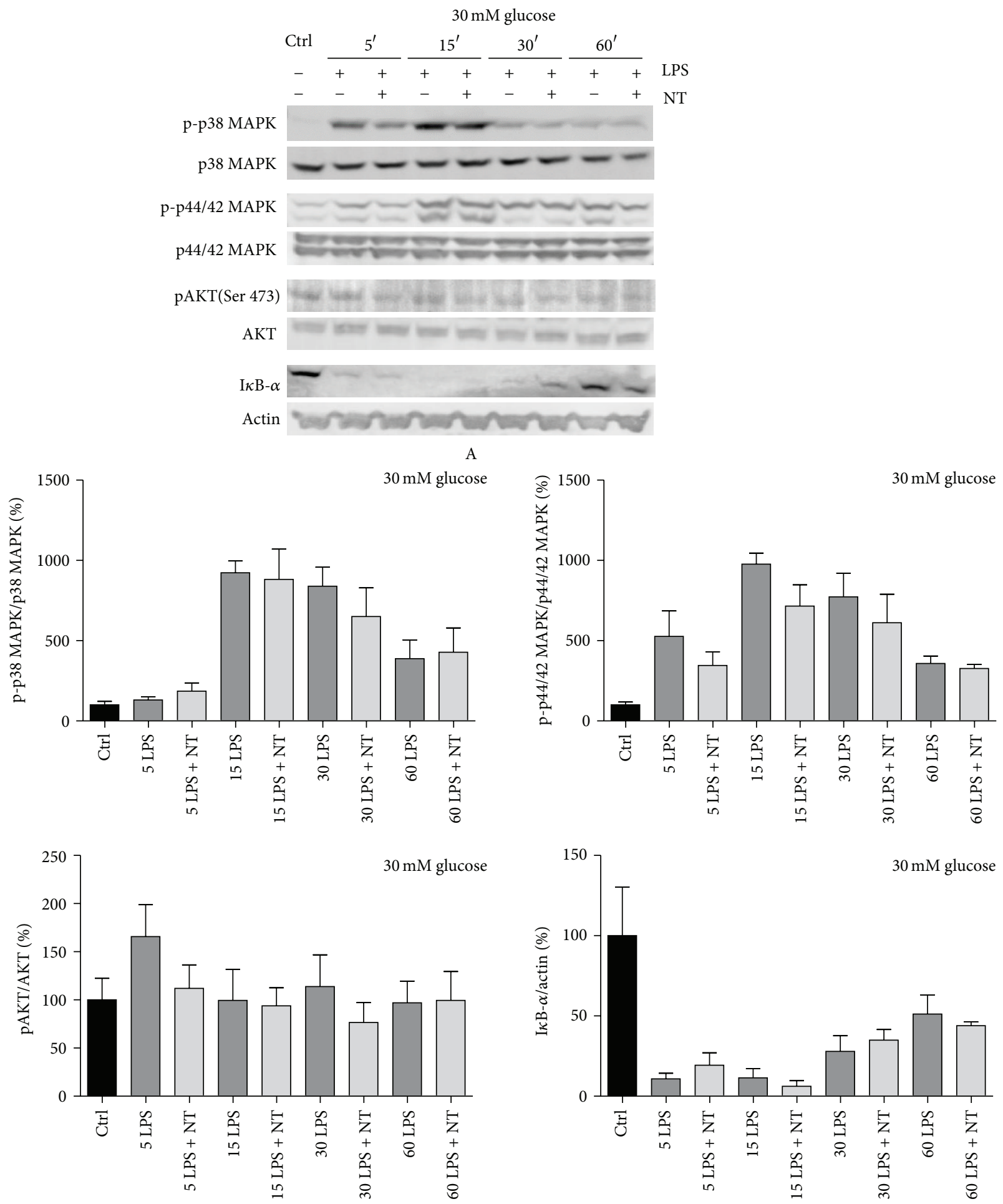

B

(b)

FIGURE 4: Modulation of LPS activated signaling pathways by NT at 10 (a) and $30 \mathrm{mM}$ glucose (b), in macrophages, by western blot (A) and relative quantification (B). Cells were plated at $1.5 \times 10^{6} /$ well and treated simultaneously with $10 \mathrm{nM} \mathrm{NT}$ and $1 \mu \mathrm{g} / \mathrm{mL}$ LPS during $5,15,30$, or 60 minutes. The lysates were probed for phospho p38 MAPK, phospho p44/42 MAPK, phospho pAKT (Ser 437), and inhibitory protein for NF- $\kappa$ B activation, I $\kappa$ B- $\alpha$ antibodies. Equal amounts of protein were evaluated with total p38 MAPK, p44/42 MAPK, AKT, and actin antibodies. The results shown are representative of four to six independent experiments with similar results. 


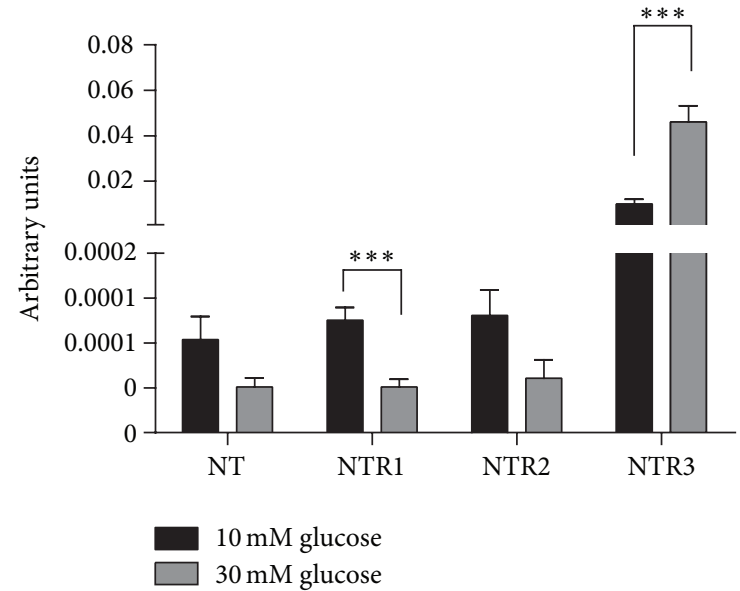

FIGURE 5: Expression of neurotensin and neurotensin receptors, NTR1, NTR2, and NTR3 in macrophages at 10 and $30 \mathrm{mM}$ glucose, by real-time PCR. Cells were plated at $2 \times 10^{6} /$ well and maintained at the indicated conditions. Total RNA was isolated as described in "Materials and Methods." The relative gene expression is indicated as arbitrary units and was obtained after normalization with the HPRT gene. Results are presented as mean \pm SEM of five to eight independent experiments. ${ }^{* * *} P<0.001$.

No significant differences were observed after NT treatment in the presence of LPS, in the presence of either 10 or $30 \mathrm{mM}$ glucose, as compared to cells treated with LPS alone.

3.5. Modulation of NT Receptors under Normal and Hyperglycemic Conditions. Gene expression results showed that under hyperglycemic conditions, NTR1 was significantly decreased $(P<0.001)$, while both NTR2 and endogenous NT were not changed, compared to normal glycemia in these cells. Interestingly, the expression of NTR3 was significantly increased under hyperglycemic conditions $(P<0.001)$ when compared to normal glycemia. In addition, the NTR3 was the most expressed receptor in macrophages under either 10 or $30 \mathrm{mM}$ glucose, as shown in Figure 5. Furthermore, we also evaluated how NT, LPS, or the cotreatment of macrophages with both agents affect the expression of endogenous NT and its receptors (Figure 6). The endogenous NT gene expression is significantly increased under NT-treated cells at $10 \mathrm{mM}$ glucose $(P<0.05)$, when compared to nontreated cells. This effect does not occur when the cells were incubated under hyperglycemia.

In addition, NT-treated cells significantly increased $(P<$ $0.01)$ NTR1 expression under $10 \mathrm{mM}$ glucose, whereas in cells maintained under $30 \mathrm{mM}$ glucose, NTR1 expression was significantly decreased $(P<0.05)$. Furthermore, in LPStreated cells, NTR1 expression was significantly increased when compared to untreated cells, both under 10 and $30 \mathrm{mM}$ of glucose. However, NT significantly decreased NTR1 expression in $30 \mathrm{mM}$ glucose $(P<0.05)$ (Figure 6). A similar pattern of expression was observed for NTR2. In NT-treated cells, NTR2 expression was increased $(P<$ 0.05 ) when compared to untreated cells in $10 \mathrm{mM}$ glucose but not in hyperglycemic condition, similar to what was previously observed for both NTR1 and endogenous NT expression. In the presence of LPS, NTR2 expression was significantly increased in $30 \mathrm{mM}$ glucose $(P<0.05)$, and this effect was not observed in NT-treated cells. Moreover, hyperglycemia did not change NTR3 expression but in the presence of NT, NTR3 expression was significantly increased (Figure 6). However, under inflammatory conditions, NTR3 gene expression was decreased compared to untreated cells, and no further changes were observed in the presence of NT, as shown in Figure 6. Interestingly, after macrophage treatment with exogenous NT, the expression of endogenous NT and its two extracellular receptors, NTR1 and NTR2 was significantly increased compared to untreated cells under $10 \mathrm{mM}$ glucose. However, this effect of NT treatment was not found in hyperglycemic condition. The opposite effect was observed for the intracellular receptor, NTR3, where hyperglycemia significantly increased NTR3 expression, but not in the presence of exogenous NT.

At the protein level, however, no differences were observed in NTR1 or NTR3 levels in $10 \mathrm{mM}$ or $30 \mathrm{mM}$ glucose either in the presence or absence of LPS (Figure 7), while NTR2 was undetectable in these cells, as we have shown previously [22].

\section{Discussion}

Platelets, neutrophils, fibroblasts, and macrophages contribute to wound healing by releasing cytokines, interleukins, and growth factors. These important cellular mediators modulate the inflammatory phase of healing [2, 8]. Macrophages, in particular, play an important role in inflammatory and immune processes. Physiological and pathophysiological events can be activated and ultimately regulated by neuropeptides, such as SP and/or NT [18, 27, 28]. It is known that local acute inflammation and migration are crucial events for proper wound healing and that chronic low-grade inflammation contributes to the impaired healing observed in diabetes $[4,5]$.

Our results demonstrate that, under hyperglycemia, NT decreases the inflammatory response of macrophages and stimulates their capacity of migration. This is, to the best of our knowledge, the first study that evaluates the effect of NT in macrophages under either inflammatory or hyperglycemic conditions or both. These findings highlight the potential therapeutic role of NT in compromised wound healing conditions, such as diabetic foot ulcers, characterized by a pathological proinflammatory status and impaired cell migration. Accordingly, in an in vitro cerebral wound healing model, NT was shown to play an important role in response to inflammation or lesions in the central nervous system through the NTR3 [29]. Moreover, Brun et al. 2005 [14] verified that NT, through NT receptor 1, stimulates epithelial restitution in intestine mucosa through a COX-2 dependent pathway in chronic inflammation of the intestine.

In addition, we observed a reduction in the macrophage migratory profile under hyperglycemic conditions, when compared to normal glycaemia. However, NT was able to 


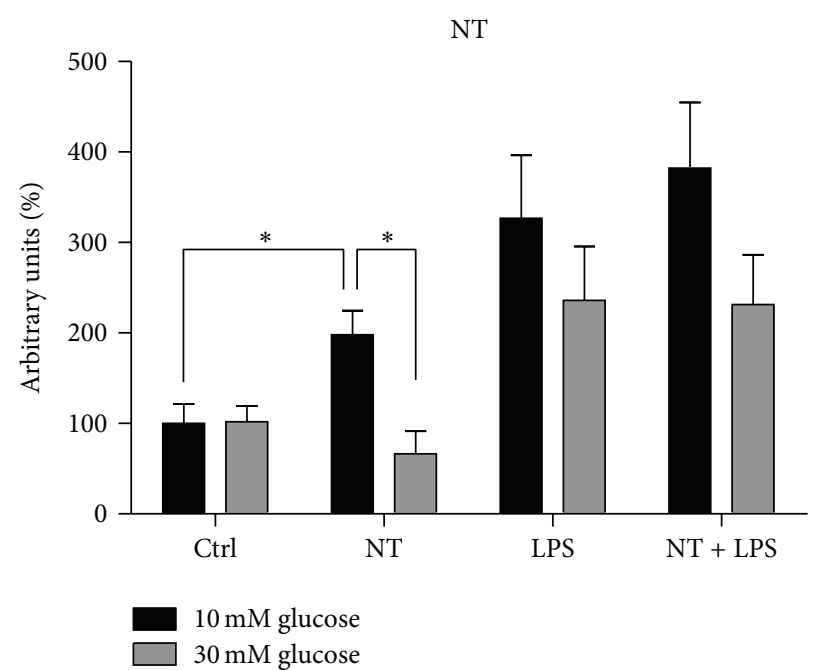

(a)

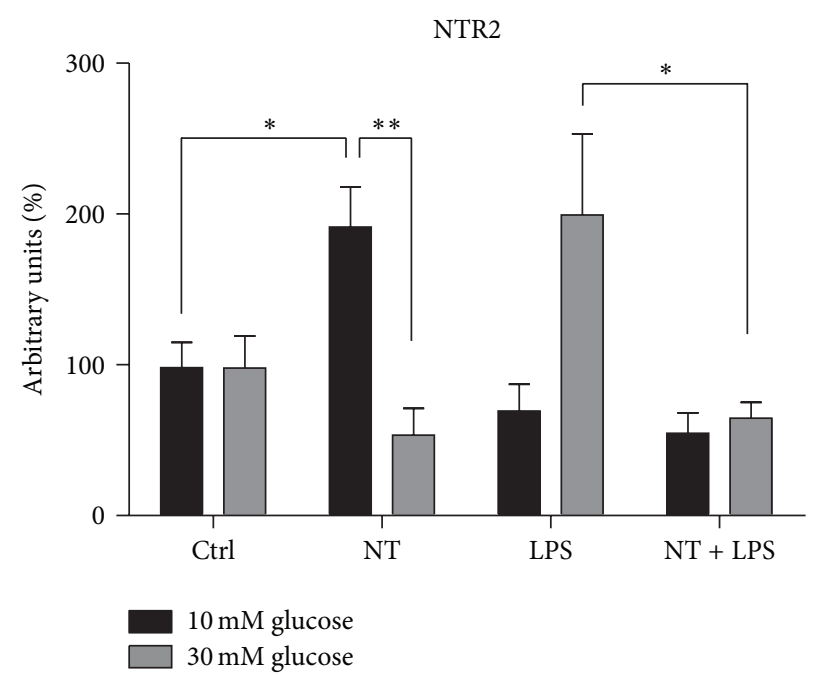

(c)

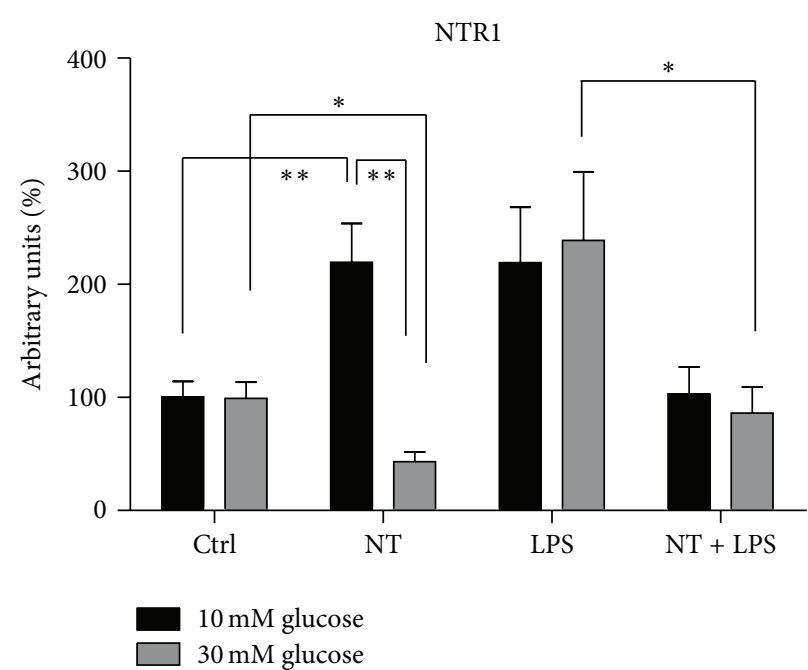

(b)

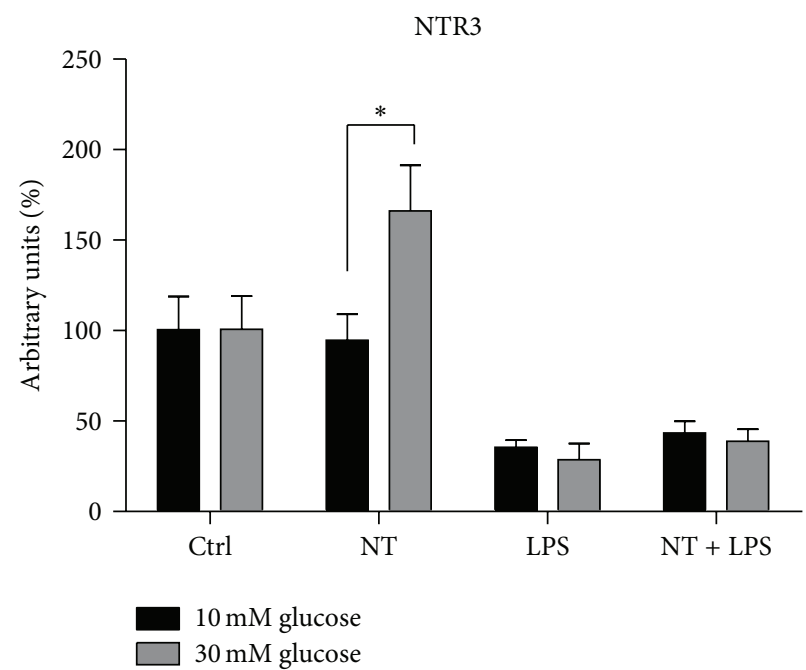

(d)

FIGURE 6: Expression of neurotensin and neurotensin receptors, NTR1, NTR2, and NTR3 in macrophages at 10 and $30 \mathrm{mM}$ glucose, by realtime PCR. Cells were plated at $2 \times 10^{6} /$ well and treated with $10 \mathrm{nM} \mathrm{NT}$ or $1 \mu \mathrm{M} / \mathrm{mL}$ LPS or both, during $6 \mathrm{~h}$. Total RNA was isolated as described in "Materials and Methods." The relative gene expression is indicated as arbitrary units and was obtained after normalization with the HPRT gene. Results are presented as mean \pm SEM of six to nine independent experiments. ${ }^{*} P<0.05 ;{ }^{* *} P<0.01$.

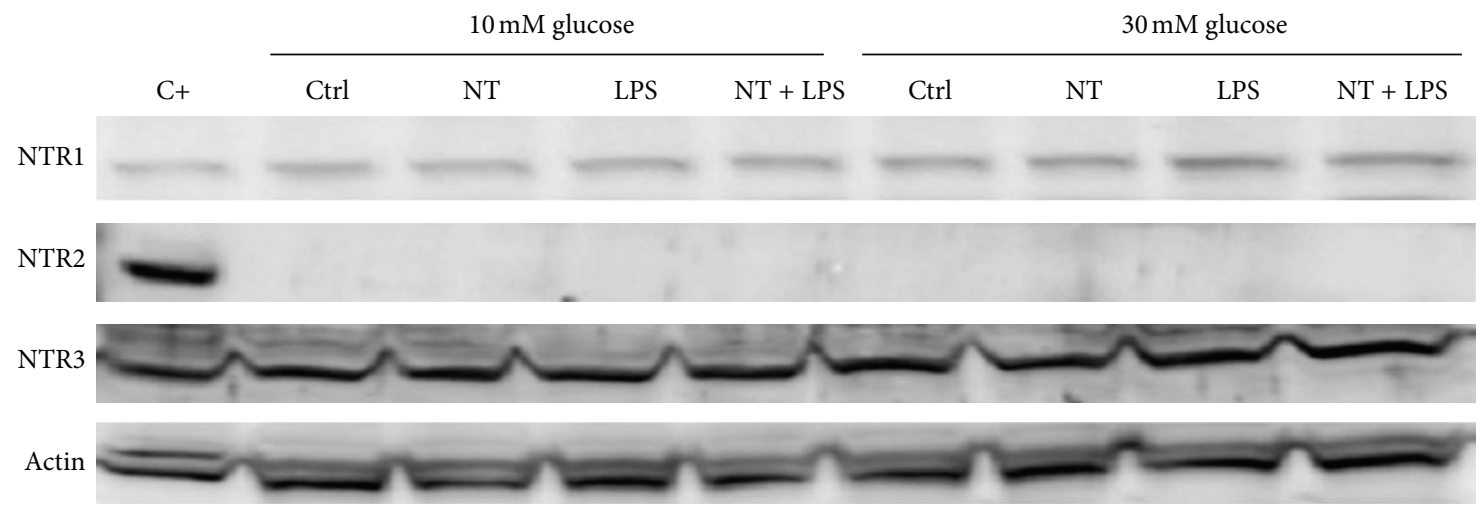

Figure 7: Neurotensin receptor protein levels in macrophages at 10 and $30 \mathrm{mM}$ glucose by western blot. Cerebral cortex lysate (C+) was used as the positive control. RAW 264.7 cells were plated at $1.5 \times 10^{6} /$ well and maintained at the indicated conditions. The lysates were probed for NTR1, NTR2, and NTR3 and actin antibodies. Three independent experiments were done for each antibody. 
highly improve the migratory capacity of these cells, either under normal or inflammatory conditions. Accordingly, Martin et al. 2003 [29] observed that NT stimulates migration of a human microglial cell line $\mathrm{C} 13 \mathrm{NJ}$ in normoglycemic conditions. Furthermore, NT significantly stimulates the phagocytic process of peritoneal macrophages from BALB/c mice [30]. Moreover, these results show that NT increases the migratory capacity of macrophages but not cell proliferation, since the MTT assay did not show any proliferative differences either in the presence or in the absence of NT. These results suggest that NT stimulates the migratory response of macrophages in the diabetic state.

The pattern of inflammatory cytokines expressed by macrophages is affected under high glucose conditions. It is known that diabetes induces the expression of various cytokines, such as TNF- $\alpha$ and IL-6, by immune cells [3133]. IL-6 is secreted by $\mathrm{T}$ cells and macrophages and acts as a pro-inflammatory cytokine to stimulate the immune response [34]. TNF- $\alpha$ is one of the major inflammatory mediators secreted by macrophages upon a proinflammatory stimulation and is expressed constitutively at a low level in monocytic cells. This basal level expression of TNF- $\alpha$ has been shown to be altered by the inflammatory milieu leading to either its upregulation or downregulation [35]. Particularly, TNF- $\alpha$ gene expression is increased in the presence of NT in $30 \mathrm{mM}$ glucose but not in $10 \mathrm{mM}$ glucose. However, in the presence of LPS, TNF- $\alpha$ expression is increased, and this effect was even more pronounced in the presence of NT, as observed in $10 \mathrm{mM}$ glucose, but not in $30 \mathrm{mM}$ glucose. IL- $1 \beta$ is produced by activated macrophages and is an important mediator of the inflammatory response; it is involved in a variety of cellular activities including cell proliferation, differentiation, and apoptosis [34]. IL-12, a cytokine produced mainly by monocytes/macrophages, is a central inducer of cell-mediated immunity that promotes the development, proliferation, and function of T helper 1 (Th1) cells [35]. Specifically, IL-1 $\beta$ and IL-12 gene expression was markedly decreased when the cells were treated with NT and LPS in $30 \mathrm{mM}$ glucose. Hill et al. [36] demonstrated that hyperglycemia inhibits IL-1 release from LPS-activated macrophages, a key mediator of the immune response against infection. Thus, different glucose concentrations can change the phenotype of macrophages leading to a switch from a proinflammatory to an anti-inflammatory profile after cell treatment with normal or high glucose concentration, respectively, as observed in other cells such as lymphocytes. This imbalance in the Th1/Th2 homeostasis contributes to the onset and progression of diabetes [37]. This may justify the prevalence of infections in poorly controlled diabetics. Our results show that NT inhibits the inflammatory response of macrophages under hyperglycemic conditions. NT induces cytokine/chemokine expression, such as macrophage inflammatory protein (MIP)-2, monocyte chemotactic protein (MCP)-1, IL-1 $\beta$, and TNF- $\alpha$ through p44/42MAPK and PI$3 \mathrm{~K}$-associated pathways in a murine microglial cell line [38]. We, on the other hand, have demonstrated that NT does not activate $\mathrm{p} 38 \mathrm{MAPK}, \mathrm{p} 44 / 42 \mathrm{MAPK}$, and PKB/AKT signaling pathways under either $10 \mathrm{mM}$ or $30 \mathrm{mM}$ glucose. More importantly, we observed a significant decrease in endogenous NT and NTR expression in hyperglycemic conditions which correlates with the high glucose-induced decrease in macrophage migration. Understanding which of these receptors might be involved in the inflammatory response of macrophages induced by NT will be important in order to better delineate the mechanisms involved in the effects of NT.

Our results demonstrate that the NTR3 was the most expressed receptor in macrophages. Similar results were obtained by Martin et al. 2003 [29] in a human microglial cell line. A downregulation of the VPAC2 (receptor for vasoactive intestinal peptide) expression has also been shown after 4 weeks of diabetes, as observed by Dvoráková et al. 2006 [39], indicating that hyperglycemia may impair signal transduction through these receptors.

Furthermore, under $10 \mathrm{mM}$ glucose, NT significantly stimulated endogenous NT, NTR1, and NTR2 expression, while no changes were observed for NTR3. On the other hand, in cells under $30 \mathrm{mM}$ glucose, NT highly increased NTR3 expression. However, NT and NTR2 protein expression was not detected in these cells (data not shown for NT). Similar results were observed previously by da Silva et al. 2011 [22], where the NTR3 was the most expressed receptor in a dendritic cell line under normoglycemic conditions. These differences in the protein expression of NT receptors could be due to the NTR3 localization, since it is an intracellular receptor, and its responses can be mostly mediated by endogenous NT. These results suggest that hyperglycemia causes the decrease in the levels of cell surface receptors, increasing the number of receptors in the light vesicle fraction without changes in the binding affinity for the peptide, and consequently, internalization of receptor 3 [40, 41]. Furthermore, under inflammatory conditions, endogenous NT is highly expressed in either the presence or absence of exogenous NT, while NTR1 and NTR2 are greatly expressed in the presence of LPS, but when NT is present, their expression returns to control levels. On the other hand, the expression of NTR3 is decreased compared to noninflammatory conditions. It is known that in peripheral tissues, such as gastrointestinal tract, desensitization of NT receptors to NT seems to be frequent $[40,42]$. Furthermore, in hyperglycemia, the loss of $G$ protein-coupled receptor function is mainly caused by reduced affinity for the neurotensin [43]. These results indicate that the effect of NT is masked by high glucose and/or reduction of the NT affinity to the receptors, as observed for other neuropeptides in similar conditions [44]. Further studies to better understand the role of NT receptors in inflammatory and hyperglycemic conditions are needed.

Furthermore, and in agreement with our results, Matyal et al. 2011 [45] observed that in diabetic patients, atrial cardiac tissue neuropeptide $\mathrm{Y}$ expression is decreased and its receptors $\mathrm{Y} 2$ and $\mathrm{Y} 5 \mathrm{mRNA}$ levels are upregulated. Altered expression of neuropeptide $\mathrm{Y}$ and its receptors during hyperglycemia may contribute to coronary artery disease, due to decreased angiogenesis, increased apoptosis, and increased vascular smooth muscle proliferation. Under these conditions, NT promotes an earlier acute inflammatory response reflecting possible beneficial effects for diabetic wound healing. 


\section{Conclusion}

These studies demonstrate that NT affects macrophage responses, both under inflammatory and hyperglycemic conditions, through the stimulation of cell migration and regulation of cytokine expression. These in vitro results are the starting point to find relevant molecules and signaling pathways triggered by NT under inflammatory and hyperglycemic conditions that are currently being confirmed both in the in vivo models as well as in the primary macrophage cultures. Based on the present results obtained, we suggest that NT administration under normal glucose conditions promotes an inflammatory response by macrophages, which may be important in the early phases of healing. When administered under hyperglycemic conditions, NT stimulates migration but inhibits the proinflammatory status of macrophages thus contributing to the resolution of inflammation and allowing the progression to the migration-remodeling phases of wound healing. These effects have the potential to be beneficial in a diabetic wound environment.

\section{Conflict of Interests}

The authors do not have any conflict of interests.

\section{Acknowledgments}

This work was financially supported by COMPETE and Fundação para a Ciência e Tecnologia (FCT-MEC) under contracts: SFRH/BD/60837/2009, SFRH/BD/30563/2006, PTDC/ SAU-BEB/71395/2006, PTDC/SAU-MII/098567/2008, and PEst-C/SAU/LA0001/2011; by EFSD/JDRF/Novo Nordisk European Programme in Type 1 Diabetes Research; and by Sociedade Portuguesa de Diabetologia.

\section{References}

[1] J. E. Shaw, R. A. Sicree, and P. Z. Zimmet, "Global estimates of the prevalence of diabetes for 2010 and 2030," Diabetes Research and Clinical Practice, vol. 87, no. 1, pp. 4-14, 2010.

[2] H. Brem and M. Tomic-Canic, "Cellular and molecular basis of wound healing in diabetes," Journal of Clinical Investigation, vol. 117, no. 5, pp. 1219-1222, 2007.

[3] C.-C. E. Lan, I.-H. Liu, A.-H. Fang, C.-H. Wen, and C.-S. Wu, "Hyperglycaemic conditions decrease cultured keratinocyte mobility: implications for impaired wound healing in patients with diabetes," British Journal of Dermatology, vol. 159, no. 5, pp. 1103-1115, 2008.

[4] A. Tellechea, E. Leal, A. Veves, and E. Carvalho, "Inflammatory and angiogenic abnormalities in diabetic wound healing: role of neuropeptides and therapeutic perspectives," The Open Circulation and Vascular Journal, vol. 3, pp. 43-55, 2010.

[5] L. Pradhan, C. Nabzdyk, N. D. Andersen, F. W. LoGerfo, and A. Veves, "Inflammation and neuropeptides: the connection in diabetic wound healing," Expert Reviews in Molecular Medicine, vol. 11, article e2, 2009.

[6] H. Kämpfer, R. Schmidt, G. Geisslinger, J. Pfeilschifter, and S. Frank, "Wound inflammation in diabetic ob/ob mice: functional coupling of prostaglandin biosynthesis to cycloox- ygenase-1 activity in diabetes-impaired wound healing," Diabetes, vol. 54, no. 5, pp. 1543-1551, 2005.

[7] T. J. Koh and L. A. DiPietro, "Inflammation and wound healing: the role of the macrophage," Expert Reviews in Molecular Medicine, vol. 13, article e23, 2011.

[8] J. D. Bagdade, R. K. Root, and R. J. Bulger, "Impaired leukocyte function in patients with poorly controlled diabetes," Diabetes, vol. 23, no. 1, pp. 9-15, 1974.

[9] T. C. Alba-Loureiro, C. D. Munhoz, J. O. Martins et al., "Neutrophil function and metabolism in individuals with diabetes mellitus," Brazilian Journal of Medical and Biological Research, vol. 40, no. 8, pp. 1037-1044, 2007.

[10] S. Khanna, S. Biswas, Y. Shang et al., "Macrophage dysfunction impairs resolution of inflammation in the wounds of diabetic mice," PLoS ONE, vol. 5, no. 3, Article ID e9539, 2010.

[11] F. O. Martinez, A. Sica, A. Mantovani, and M. Locati, "Macrophage activation and polarization," Frontiers in Bioscience, vol. 13, no. 2, pp. 453-461, 2008.

[12] L. F. de Souza, F. R. Jardim, I. P. Sauter, M. M. de Souza, and E. A. Bernard, "High glucose increases RAW 264.7 macrophages activation by lipoteichoic acid from Staphylococcus aureus," Clinica Chimica Acta, vol. 398, no. 1-2, pp. 130-133, 2008.

[13] I. J. Elenkov, "Neurohormonal-cytokine interactions: implications for inflammation, common human diseases and wellbeing," Neurochemistry International, vol. 52, no. 1, pp. 40-51, 2008.

[14] P. Brun, C. Mastrotto, E. Beggiao et al., "Neuropeptide neurotensin stimulates intestinal wound healing following chronic intestinal inflammation," American Journal of Physiology, vol. 288, no. 4, pp. G621-G629, 2005.

[15] A. V. Delgado, A. T. McManus, and J. P. Chambers, "Exogenous administration of substance $P$ enhances wound healing in a novel skin-injury model," Experimental Biology and Medicine, vol. 230, no. 4, pp. 271-280, 2005.

[16] M. Toda, T. Suzuki, K. Hosono et al., "Roles of calcitonin gene-related peptide in facilitation of wound healing and angiogenesis," Biomedicine and Pharmacotherapy, vol. 62, no. 6, pp. 352-359, 2008.

[17] L. Pradhan, X. Cai, S. Wu et al., "Gene expression of proinflammatory cytokines and neuropeptides in diabetic wound healing," Journal of Surgical Research, vol. 167, no. 2, pp. 336342, 2011.

[18] M. H. Jiang, E. Chung, G. F. Chi, W. Ahn, J. E. Lim, H. S. Hong et al., "Substance P induces M2-type macrophages after spinal cord injury," Neuroreport, vol. 23, pp. 786-792, 2012.

[19] L. H. Lazarus, M. R. Brown, and M. H. Perrin, "Distribution, localization and characteristics of neurotensin binding sites in the rat brain," Neuropharmacology, vol. 16, no. 9, pp. 625-629, 1977.

[20] D. Zhao, Y. Zhan, H. Zeng, H.-W. Koon, M. P. Moyer, and C. Pothoulakis, "Neurotensin stimulates interleukin-8 expression through modulation of $\mathrm{I} \kappa \mathrm{B} \alpha$ phosphorylation and $\mathrm{p} 65$ transcriptional activity: involvement of protein kinase $\mathrm{C} \alpha$," Molecular Pharmacology, vol. 67, no. 6, pp. 2025-2031, 2005.

[21] H. S. Kim, S. Yumkham, J. H. Choi et al., "Neurotensin enhances nitric oxide generation via the JAK2-STAT1 pathway in murine macrophage RAW 264.7 cells during costimulation with LPS and IFN $\gamma$," Neuropeptides, vol. 40, no. 3, pp. 221-229, 2006.

[22] L. da Silva, B. M. Neves, L. Moura, M. T. Cruz, and E. Carvalho, "Neurotensin downregulates the pro-inflammatory properties of skin dendritic cells and increases epidermal growth factor 
expression," Biochimica et Biophysica Acta, vol. 1813, no. 10, pp. 1863-1871, 2011.

[23] H.-P. Hartung, "Activation of macrophages by neuropeptides," Brain Behavior and Immunity, vol. 2, no. 4, pp. 275-281, 1988.

[24] D. Ganea and M. Delgado, "Neuropeptides as modulators of macrophage functions. Regulation of cytokine production and antigen presentation by VIP and PACAP," Archivum Immunologiae et Therapiae Experimentalis, vol. 49, no. 2, pp. 101-110, 2001.

[25] J.-P. Vincent, J. Mazella, and P. Kitabgi, "Neurotensin and neurotensin receptors," Trends in Pharmacological Sciences, vol. 20, no. 7, pp. 302-309, 1999.

[26] M. W. Pfaffl, "A new mathematical model for relative quantification in real-time RT-PCR," Nucleic Acids Research, vol. 29, no. 9, article e45, 2001.

[27] H. K. Jeon, N. P. Jung, I. H. Choi, Y. K. Oh, H. C. Shin, and B. J. Gwag, "Substance P augments nitric oxide production and gene expression in murine macrophages," Immunopharmacology, vol. 41, no. 3, pp. 219-226, 1999.

[28] R. Yaraee, M. Ebtekar, A. Ahmadiani, and F. Sabahi, "Neuropeptides (SP and CGRP) augment pro-inflammatory cytokine production in HSV-infected macrophages," International Immunopharmacology, vol. 3, no. 13-14, pp. 1883-1887, 2003.

[29] S. Martin, J.-P. Vincent, and J. Mazella, "Involvement of the neurotensin receptor-3 in the neurotensin-induced migration of human microglia," Journal of Neuroscience, vol. 23, no. 4, pp. 1198-1205, 2003.

[30] M. De La Fuente, J. J. Garrido, R. M. Arahuetes, and A. Hernanz, "Stimulation of phagocytic function in mouse macrophages by neurotensin and neuromedin N," Journal of Neuroimmunology, vol. 42, no. 1, pp. 97-104, 1993.

[31] S. Devaraj, S. K. Venugopal, U. Singh, and I. Jialal, "Hyperglycemia induces monocytic release of interleukin- 6 via induction of protein kinase C- $\alpha$ and $-\beta$," Diabetes, vol. 54 , no. 1 , pp. 85-91, 2005.

[32] E. Hatanaka, P. T. Monteagudo, M. S. M. Marrocos, and A. Campa, "Neutrophils and monocytes as potentially important sources of proinflammatory cytokines in diabetes," Clinical and Experimental Immunology, vol. 146, no. 3, pp. 443-447, 2006.

[33] M. R. Dasu, S. Devaraj, L. Zhao, D. H. Hwang, and I. Jialal, "High glucose induces toll-like receptor expression in human monocytes Mechanism of activation," Diabetes, vol. 57, no. 11, pp. 3090-3098, 2008.

[34] J. M. Cavaillon, "Cytokines and macrophages," Biomedicine and Pharmacotherapy, vol. 48, no. 10, pp. 445-453, 1994.

[35] N. Silswal, A. K. Singh, B. Aruna, S. Mukhopadhyay, S. Ghosh, and N. Z. Ehtesham, "Human resistin stimulates the proinflammatory cytokines TNF- $\alpha$ and IL-12 in macrophages by NF- $\kappa$ B-dependent pathway," Biochemical and Biophysical Research Communications, vol. 334, no. 4, pp. 1092-1101, 2005.

[36] J. R. Hill, G. Kwon, C. A. Marshall, and M. L. McDaniel, "Hyperglycemic levels of glucose inhibit interleukin 1 release from RAW 264.7 murine macrophages by activation of protein kinase C," Journal of Biological Chemistry, vol. 273, no. 6, pp. 3308-3313, 1998.

[37] C. Sia, "Imbalance in Th cell polarization and its relevance in type 1 diabetes mellitus," Review of Diabetic Studies, vol. 2, pp. 182-186, 2005.

[38] E. Dicou, J.-P. Vincent, and J. Mazella, "Neurotensin receptor3/sortilin mediates neurotensin-induced cytokine/chemokine expression in a marine microglial cell line," Journal of Neuroscience Research, vol. 78, no. 1, pp. 92-99, 2004.
[39] M. C. Dvoráková, U. Pfeil, J. Kuncová et al., “Down-regulation of vasoactive intestinal peptide and altered expression of its receptors in rat diabetic cardiomyopathy," Cell and Tissue Research, vol. 323, no. 3, pp. 383-393, 2006.

[40] E. Hermans and J.-M. Maloteaux, "Mechanisms of regulation of neurotensin receptors," Pharmacology and Therapeutics, vol. 79, no. 2, pp. 89-104, 1998.

[41] J. Mazella, "Sortilin/neurotensin receptor-3: a new tool to investigate neurotensin signaling and cellular trafficking?" Cellular Signalling, vol. 13, no. 1, pp. 1-6, 2001.

[42] F. Mule, R. Serio, and A. Postorino, "Motility pattern of isolated rat proximal colon and excitatory action of neurotensin," European Journal of Pharmacology, vol. 275, no. 2, pp. 131-137, 1995.

[43] S. Hashim, Y. Li, and M. B. Anand-Srivastava, "G proteinlinked cell signaling and cardiovascular functions in diabetes/hyperglycemia," Cell Biochemistry and Biophysics, vol. 44, no. 1, pp. 51-64, 2006.

[44] A. Akabayashi, C. T. B. V. Zaia, I. Silva, H. J. Chae, and S. F. Leibowitz, "Neuropeptide $\mathrm{Y}$ in the arcuate nucleus is modulated by alterations in glucose utilization," Brain Research, vol. 621, no. 2, pp. 343-348, 1993.

[45] R. Matyal, F. Mahmood, M. Robich et al., "Chronic type II diabetes mellitus leads to changes in neuropeptide y receptor expression and distribution in human myocardial tissue," European Journal of Pharmacology, vol. 665, no. 1-3, pp. 19-28, 2011. 


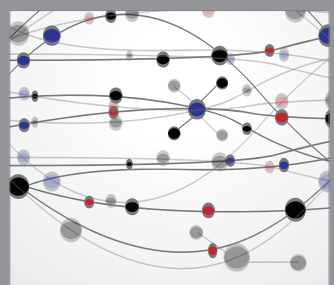

The Scientific World Journal
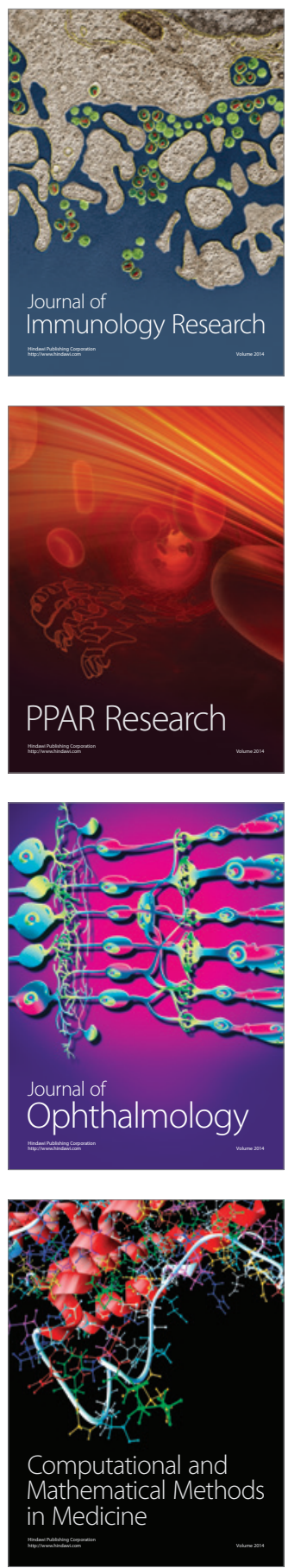

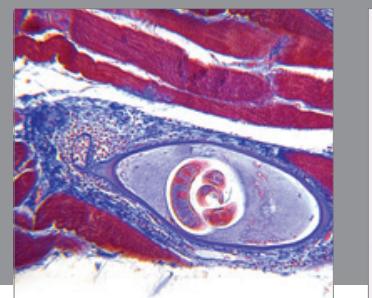

Gastroenterology

Research and Practice
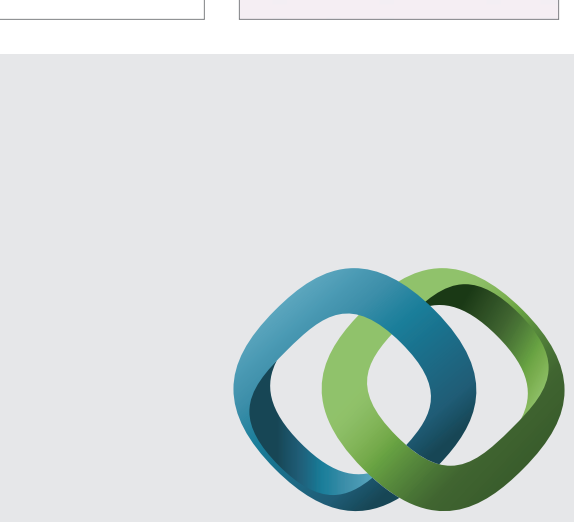

\section{Hindawi}

Submit your manuscripts at

http://www.hindawi.com
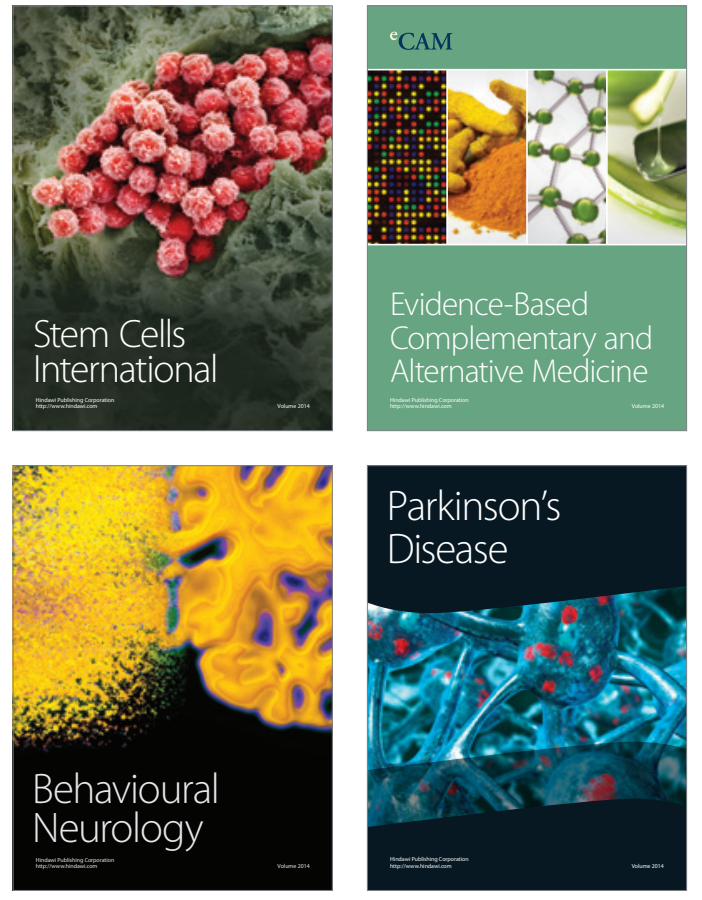
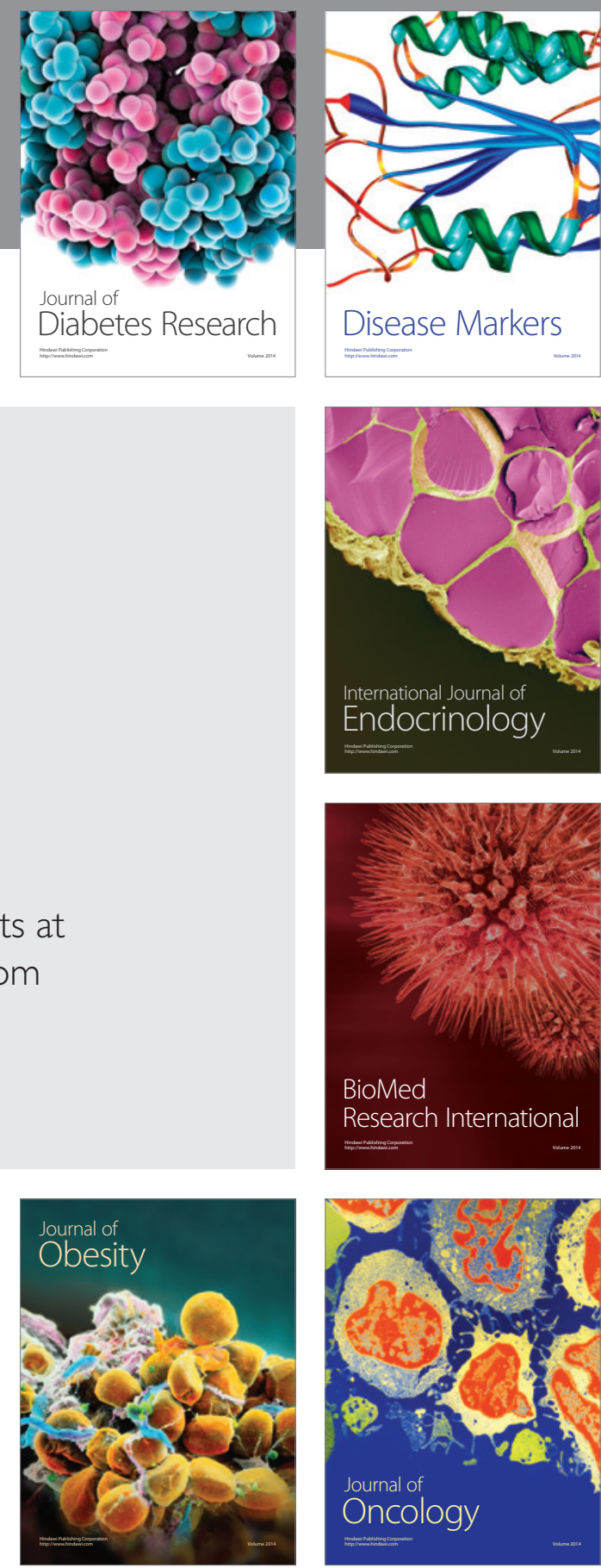

Disease Markers
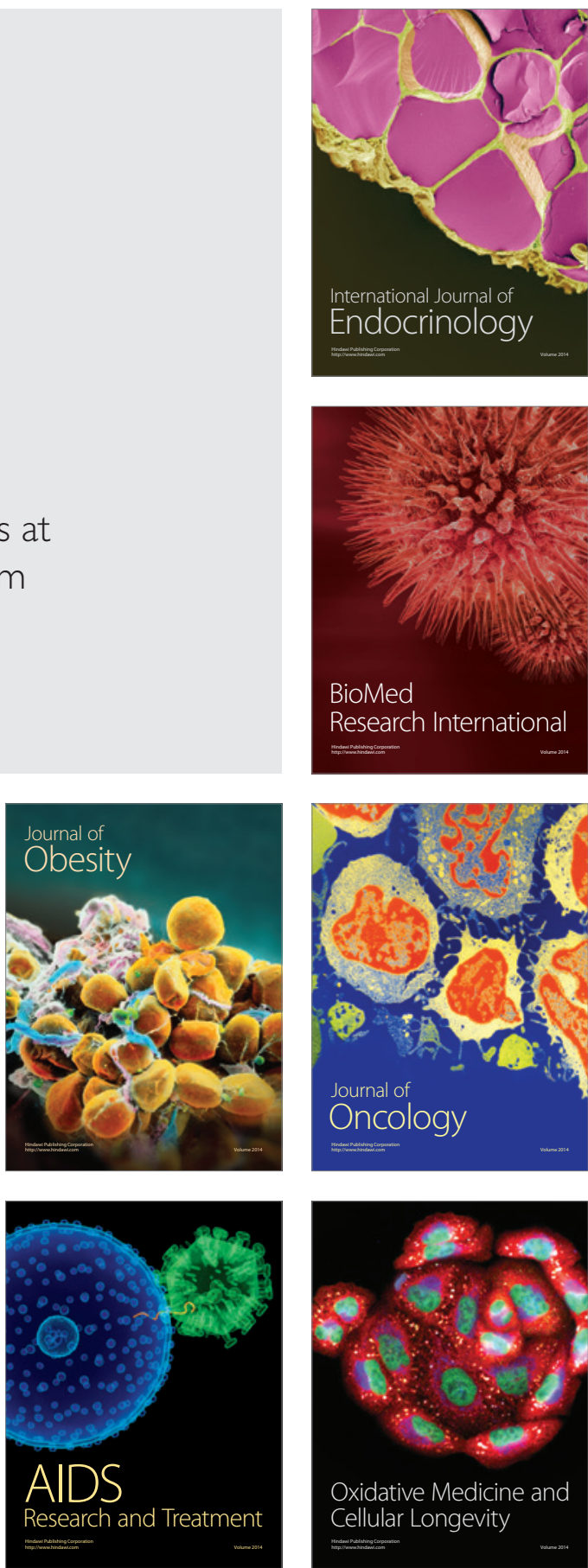